\title{
A qualidade de vida no trabalho dos docentes de bacharelado e licenciatura de uma instituição pública de ensino superior
}

\section{Quality of work life of bachelor and licentiate's degree professors of a public university}

\author{
Elizabete Ribas Lustoza \\ Universidade Estadual do Centro-Oeste - UNICENTRO - Guarapuava - Brasil \\ betinha@unicentro.br \\ Silvio Roberto Stefano \\ Universidade Estadual do Centro-Oeste - UNICENTRO - Guarapuava - Brasil \\ professor-silvio@hotmail.com \\ Marcia Aparecida Zampier \\ Universidade Estadual do Centro-Oeste - UNICENTRO - Guarapuava - Brasil \\ marciazampier@gmail.com
}

\begin{abstract}
Resumo
A qualidade de vida no trabalho nas organizações tem se caracterizado como um fenômeno biopsicossocial, e com essas dimensões biológicas, psicológicas e sociais o ser humano reage às situações da vida, dentro ou fora da organização. O presente estudo foi elaborado com a finalidade de verificar o nível de satisfação com a qualidade de vida no cotidiano do trabalho (QVT) dos docentes universitários dos setores da Universidade Estadual do Centro-Oeste, UNICENTRO. Para tanto, foi realizada primeiramente, a pesquisa bibliográfica, relacionada ao tema, depois foi realizada a pesquisa de campo com cento e setenta e sete docentes, utilizando como instrumento um questionário de auto relato constituído de quarenta e uma questões aplicado durante os meses de maio e junho, por meio de estudo do caso predominantemente quantitativo. As variáveis foram classificadas em biológica, psicológica, social e organizacional. A partir destes dados, realizou-se uma análise descritiva. Nas considerações finais demonstrou-se que, os docentes de bacharelado e licenciatura estão parcialmente satisfeitos em alguns aspectos considerados.
\end{abstract}

Palavras-chave: qualidade de vida, qualidade de vida no trabalho, satisfação, estresse.

\section{Abstract}

The quality of work life in organizations has been characterized as a biopsychosocial phenomenon, and these biological, psychological and social human being reacts to life situations within or outside the organization. The present study was designed in order to verify the level of satisfaction with the quality of life in daily work (QWL) of academics sectors State University Midwest, UNCENTRO. Therefore, we performed a literature search primarily related to the theme, was held after the field survey with one hundred seventy-seven teachers using a questionnaire as a tool of self-report consists of forty-one questions applied during the months of May and June, through case study predominantly quantitative. The variables were classified into biological, psychological, social and organizational. From these data, we carried out a descriptive analysis. In the final it was 
shown that teachers baccalaureate degree and are partially satisfied in some aspects considered.

Keywords: quality of life, quality of work life, satisfaction, stress.

\section{Introdução}

A qualidade de vida é um assunto relevante no mundo contemporâneo, por ser um resultado de interação entre as expectativas e realizações de uma pessoa, perspectivas de futuro, e estar diretamente relacionada com a percepção que cada um tem de si, dos outros e do mundo que rodeia, torna-se, dessa maneira, objeto de pesquisa.

A abordagem dos conceitos de qualidade de vida no contexto da linguagem científica, nas diferentes áreas do saber, como a saúde, a economia, a sociologia, na educação e na psicologia, e sua a concepção, diferencia-se de pessoa para pessoa e tende a mudar no decorrer da vida de cada um pela própria inserção na sociedade (NAHAS, 2006).

Em 1995, a Organização Mundial da Saúde (OMS) declara que a qualidade de vida é "a percepção do indivíduo de sua posição na vida no contexto da cultura e sistemas de valores nas quais ele vive e em relação a seus objetivos, expectativas, padrões e preocupações" (WHOQOL GROUP, 1995). Portanto, a qualidade de vida não se refere somente à ausência de doença, mas também um estado de bem estar físico, mental e social. São essas colocações que levam o indivíduo a buscar objetivos e ter perspectivas de futuro para sua realização pessoal.

A qualidade de vida está diretamente relacionada ao trabalho e também tem relação fundamental com a vida do indivíduo fora da empresa. A QVT, não representa apenas o indivíduo dentro da organização, mas também na relação entre a qualidade de vida dentro e fora do ambiente de trabalho. Tais aspectos são indissociáveis.

O bem estar é fundamental para a vida pessoal e para a sua capacidade em realizar as atividades profissionais, pois pelo menos um terço do dia é gasto no trabalho. É preciso salientar que o trabalho não pode ser considerado apenas uma fonte de renda, mas um meio para satisfazer outras necessidades, como: aceitação, autoestima, reconhecimento e relacionamento interpessoal.

Entende-se que a qualidade de vida, relaciona-se com a percepção individual sobre a vida de cada um, também é o sistema de valores do indivíduo, além do mais o desenvolvimento social no trabalho e na família, bem como o desenvolvimento econômico e o desenvolvimento humano, são processos que estão em constante mudança, assim como a evolução técnico-científica relacionada às necessidades individuais.

A partir destes conceitos pode-se compreender que a qualidade de vida é importante não só no ponto de vista do trabalhador, mas também das organizações e da sociedade em geral.

O objetivo geral desta pesquisa foi, a partir dos conceitos adquiridos sobre qualidade de vida, qualidade de vida no trabalho e estresse no trabalho, identificar a percepção dos docentes dos setores: Setor de Ciências Sociais Aplicadas, SESA e Setor de Humanas, Letras e Artes, SEHLA da Universidade Estadual do Centro-Oeste, Unicentro, Campus Santa Cruz, em Guarapuava a respeito da satisfação qualidade de vida no seu trabalho, submetendo-os a apreciação por meio de questionário. Para atingir o objetivo, foi utilizado uma amostragem dos docentes, com enfoque quantitativo, por meio de questionários de auto relato sobre a percepeção da qualidade de vida no trabalho.

O presente artigo está estruturado da seguinte forma: fundamentação teórica, conceito e definições de qualidade de vida, qualidade de vida no trabalho, estresse, tipos de estresse, causas do estresse, consequências do estresse, gestão de qualidade de vida 
e qualidade de vida no trabalho, método, resultados, análise e considerações finais.

\section{Fundamentação teórica}

\subsection{Conceitos e definições qualidade de vida, qualidade de vida no trabalho e estresse}

O trabalho tem grande influência na qualidade vida das pessoas, pois boa parte do dia é dedicada às atividades profissionais. Segundo o dicionário Michaelis (1998, p. 2267), uma das definições para a palavra satisfação é a "sensação agradável que sentimos quando as coisas correm à nossa vontade ou se cumprem à nosso contento". Utilizando-se desta definição, foi desenvolvida a pesquisa sobre a satisfação dos docentes a respeito das condições de qualidade de vida em seu trabalho.

O estudo da fundamentação teórica sobre a qualidade de vida, QVT, o estresse, as relações com o ambiente organizacional e com o cotidiano da vida pessoal, serviu de subsídio para a abordagem referente às questões sobre a satisfação da qualidade de vida no trabalho dentro de uma instituição de ensino superior, identificando o nível de percepção em relação com a QVT.

Para Lipp (1994, p. 13) "[...] Por qualidade de vida entendemos o viver que é bom e compensador em pelo menos quatro áreas: social, afetiva, profissional e a que se refere à saúde (...). O viver bem refere-se a ter uma vida bem equilibrada em todas as áreas".

Qualidade de vida pode ser entendida como a percepção de bem-estar, a partir das necessidades individuais, ambiental social, econômica e também da expectativa de vida. Do ponto de vista biopsicossocial, a pesquisa elaborada por Limongi-França (2004), entende e vê o indivíduo como um todo, abarcando os fatores biológico, psicológico e o social, os quais contribuem para a formação do ser humano. Entender o ser humano e as reações, tanto na saúde como na ausência de saúde, de uma forma mais generalizada e coerente, de acordo com a Organização Mundial da Saúde (WHOQOL, 1995), é: "o completo bem estar biológico, psicológico e social e não apenas a ausência de doença". A Organização Mundial da Saúde, OMS preconiza que ser saudável é ter uma condição de bem estar que inclui, além do bom funcionamento do corpo, o bem estar espiritual e social, por isso a QVT e a saúde estão inter-relacionadas.

Ainda, de acordo com Limongi-França (2004) a palavra biopsicossocial se origina na medicina psicossomática, que propõe uma visão abrangente, integral e holística do ser humano. Assim, todo ser humano possui potencialidades biológicas, psicológicas e sociais que respondem às condições de vida.

O conceito de Desenvolvimento Humano parte do pressuposto de que para aferir o avanço da qualidade de vida de uma população é preciso ir além do viés econômico e considerar três dimensões básicas do desenvolvimento humano: saúde, educação e renda. Sendo esse conceito a base do Índice de Desenvolvimento Humano (IDH) e PNUD Brasil - Programa de Desenvolvimento Humano das Nações.

O Índice de Desenvolvimento Humano (IDH) (PNUD, 2015), é entendido como "uma medida resumida do progresso a longo prazo em três dimensões básicas do desenvolvimento humano: renda, educação e saúde." Ela agrega as medidas comparativas expectativa de vida ao nascer, acesso ao conhecimento e ao PIB, exemplos de índices de qualidade de vida das populações.

Mas, também, para aferir a qualidade de vida, o Índice de Desenvolvimento Humano, (IDH) o qual é calculado anualmente pelo Programa das Nações Unidas para o Desenvolvimento (PNUD, 2015), serve de indicador para o bem-estar humano e envolve atualmente cento e oitenta países. Os indicadores de qualidade de vida podem ser aferidos localmente, considerando três contextos: as condições econômicas (renda, consumo, mercado de trabalho e mercado de habitação); as condições sociais (dinâmica 
cultural, educação, segurança, saúde e comunicação social); e as condições ambientais (espaços verdes, clima, ruído, qualidade do ar, qualidade da água, tratamento dado ao lixo).

O PNUD (2015) descreve que o relatório do Desenvolvimento Humano de 2014, pelo Programa das Nações Unidas para o Desenvolvimento (PNUD), classifica o Brasil na 75ำ posição entre 188 países avaliados. Nesse aspecto, o Brasil perdeu uma posição em relação ao ano de 2013 , com índice 0,755 na escala que vai de zero a um.

De acordo com o PNUD (2015), o Estado do Paraná, situado na região sul do país, ocupa o quinto lugar no ranking nacional, com índices de 0,749 em 2010. O Paraná é um Estado que tem o desenvolvimento econômico e certo respeito ao ambiente.

Nahas (2006) argumenta sobre os fatores que podem influenciar na Qualidade de Vida, que são os fatores socioambientais e os fatores individuais, conforme o quadro a seguir:

\begin{tabular}{|c|c|}
\hline Quadro 1: Indicadores socioambientais e individuais da Qualidade de Vida \\
\hline Indicadores Socioambientais & Indicadores Individuais \\
\hline Assistência Médica & Atividade Física regular \\
\hline Condições de trabalho e remuneração & Comportamento preventivo \\
\hline Educação & Controle do estresse \\
\hline Meio ambiente & Estilo de vida saudável \\
\hline Moradia & Hábitos alimentares adequados \\
\hline Opções de lazer & Hereditariedade \\
\hline Segurança & Relacionamentos sociais \\
\hline Transporte & \\
\hline
\end{tabular}

Fonte: Adaptação de Nahas (2006).

Esses indicadores sociais, ambientais e os individuais influenciam na qualidade de vida das pessoas. Como se não bastasse às preocupações profissionais, existem as preocupações individuais do funcionário, toda a história de vida pessoal - conflitos, frustrações, desavenças conjugais, preocupação com os filhos, interesses e necessidades particulares - que o acompanha em todos os momentos e no trabalho não seria diferente (BALLONE, 2002).

Os conceitos de Qualidade de Vida e QVT entrelaçam-se, existindo uma preocupação com o equilíbrio de satisfação pessoal e profissional, além do bem-estar proporcionado.

Limongi-França (2004, p. 296), para uma compreensão mais abrangente, define a qualidade de vida no trabalho como conjunto de ações de uma empresa, no sentido de implantar melhorias e inovações gerenciais, tecnológicas e estruturais no ambiente de trabalho. Baseado nesse conceito deve-se levar em conta alguns fatores, são eles: riscos físicos, químicos e biológicos, além da carga de trabalho físico, cognitiva e psíquica. Tais fatores podem influenciar diretamente ou indiretamente na saúde do colaborador e, como consequência, a produtividade da organização.

Sob o ponto de vista de Rossi, Quick e Perrewé (2009, p. 275), "QVT é o conjunto de escolhas de bem-estar único e individualizado que proporciona autoestima positiva, percepção de equilíbrio, hábitos saudáveis e prontidão para o desempenho no trabalho saudável".

Diversos fatores podem interferir na Qualidade de Vida, destacando-se os relacionados ao trabalho. Segundo Fleck et al. (1999), o choque entre a estrutura organizacional e a estrutura psicofísica do trabalhador pode levar a diminuir sua a qualidade de vida. A qualidade de vida no trabalho pode referir-se aos aspectos favoráveis ou desfavoráveis no ambiente profissional. Segundo Limongi-França (2004) as pressões no trabalho prejudicam a satisfação com a QVT, levando ao desgaste tanto emocional como físico.

De acordo com Azevedo e Kitamura (2006, p. 138) "especificamente em relação ao trabalho, há um duplo reconhecimento por partes dos estudiosos em relação ao estresse": 
diversos aspectos do ambiente organizacional do trabalho podem ser geradores de estresse e, por outro lado, sabe-se que um tipo de estresse está associado ao rebaixamento da qualidade de vida dos trabalhadores.

O significado do termo estresse vem da Física, sendo que para esse campo da ciência, tem sentido de deformidade que uma estrutura sofre quando é submetida a um esforço (FRANÇA; RODRIGUES, 2002). Já o médico Hans Selye, transpôs tal termo para o campo da medicina e da biologia, neles o estresse é o esforço de adaptação do organismo para enfrentar situações que considere ameaçadoras a sua vida e ao seu equilíbrio interno.

"As primeiras referências à palavra stress, com significado de aflição e adversidade são do século XIV. No século XVII, o vocábulo de origem latina passou a ser utilizado em inglês para designar a opressão, desconforto e adversidade" (LIPP; ROCHA, 1996, p. 37). Já Molina (1996, p.18), define o estresse como:

[...] situação de tensão aguda ou crônica que produz uma mudança no comportamento físico e no estado emocional do indivíduo e uma resposta de adaptação psicofisiológica que pode ser negativa ou positiva no organismo.

Estresse no trabalho e Qualidade de Vida no Trabalho (QVT) tem sido estudado no Brasil e em outros países, pela incidência demasiadamente elevada do sofrimento mental levando o indivíduo ao adoecimento físico e psicológico, tendo como consequência, a baixa produtividade. No Brasil, já foram atualizadas normas regulamentando o assunto, tais como: a) Nova Regulamentação sobre Doenças Profissionais e do Trabalhador do Decreto no 3048 do MPAS em 06/05/1999, b) Lista de Doenças Relacionadas ao Trabalho da Portaria no 1.339 em 18/11/1999, que trata um capítulo específico sobre Transtornos Mentais e do Comportamento relacionados ao Trabalho. Sendo o Grupo V, da CID 10, F43, reações ao estresse graves e transtornos de adaptação.

Embora haja várias definições para o estresse, podemos perceber que todas possuem um ponto em comum: a reação do organismo frente à diversas situações que pedem uma adaptação. É necessário entender que não são apenas as situações ruins que deixam as pessoas estressadas, todas as grandes transformações pelas quais todos passam, sejam elas boas ou más, podem desenvolver o estresse.

O estresse pode ser dividido em: eustress - tensão como equilíbrio entre esforço, tempo, realização e resultados; e distress - tensão com rompimento e equilíbrio biopsicossocial por excesso ou falta de esforço, incompatível com o tempo, resultados e avaliações (FRANÇA; RODRIGUES, 2002).

Limongi-França e Rodrigues (2005) entendem que o estresse pode ser encontrado em duas dimensões. $O$ eustress, quando o estresse pode ter um resultado positivo, e o distress, quando tem um resultado negativo, em relação ao esforço gerado pela tensão mobilizada pela pessoa. $O$ eustress é entendido com o equilíbrio entre esforço, tempo, realização e resultados, sendo um aspecto positivo de lidar com as pressões, nele a pessoa consegue vencer desafios. Já o distress é o termino do equilíbrio biopsicossocial, por excesso ou falta de esforço, incompatível com tempo, realização e resultados. Nesta pessoa não consegue vencer os desafios e percebe-os como ameaça, gerando um desequilíbrio patológico, uma debilidade física e psicológica de variáveis em todos os aspectos da vida.

Partindo deste princípio, o comportamento é determinado pela inter-relação da pessoa com o grupo ao qual pertence. Levando em conta, não só a resposta de um estímulo, mas o conjunto de fatores, da pessoa do ambiente e da circunstância entre eles.

De acordo com Lipp e Rocha (1996), o estresse foi dividido por Selye em três fases que são: alerta, resistência e exaustão. A fase de alerta é considerada positiva do estresse, na qual a descarga de adrenalina intensa torna o indivíduo mais atento, mais produtivo e motivado. A fase da resistência é caracterizada pela produção de cortisol, o 
organismo da pessoa que fica nesta fase de alerta por grandes períodos ou se novos estressores se acumulam, entra em ação na tentativa de restabelecer a homeostase (equilíbrio da vida) perdida ficando vulnerável a vírus e bactérias. A última fase do estresse é a exaustão considerada patológica, na qual um importante desequilibro interior acontece: a pessoa entra em depressão, não consegue mais viver o dia a dia, e sua produtividade é nula.

\subsection{Gestão da qualidade de vida no trabalho}

A gestão da Qualidade de Vida é entendida por Limongi-França (2004, p. 167) como:

A capacidade de administrar o conjunto de ações, incluindo diagnóstico, implantação de melhorias e inovações gerenciais, tecnológicas e estruturais no ambiente de trabalho alinhada e construída na cultura organizacional, com a prioridade absoluta para o bem-estar das pessoas.

A preocupação com a saúde dos colaboradores das organizações tornou-se objeto de estudo, pois aborda aspectos de interesses tanto das organizações como dos colaboradores, pois estes, estando satisfeitos, produzem melhor resultado para a organização.

O estresse é relacionado com a falta de qualidade de vida, tanto na vida pessoal como na vida profissional. A pessoa estando bem psicologicamente e fisicamente, certamente terá um rendimento melhor do que aquela que está debilitada. Por isso existe uma estreita relação entre qualidade de vida, qualidade de vida no trabalho e estresse.

Alguns fatores emocionais relacionados ao emprego fazem com que a pessoa mantenha-se excessivamente estressada, são eles: a impressão de insuficiência profissional, a sensação de instabilidade no emprego, a pressão para provar eficiência, a falta de visão sobre a relevância social de seu trabalho, a percepção de ausência de reconhecimento de seus esforços e a sensação de estar sempre cometendo um erro.

De acordo com Limongi-França (2008, p. 25-26), na cultura organizacional há alternativas para estudar pessoas na organização, que podem contribuir para melhoria da qualidade de vida no trabalho, são elas: teoria sobre pessoas na empresa, sobre a psicologia ambiental, sobre segurança no trabalho, sobre higiene mental do trabalhador e a saúde do trabalhador.

"É possível pensar que existe qualidade de vida no trabalho quando os membros de uma organização são capazes de satisfazer as necessidades pessoais importantes através da vivência na mesma" (SILVA, 2000, p. 23). Segundo o autor, satisfação das necessidades básicas da pessoa tem de estar atrelado ao trabalho, e assim garantir a qualidade de vida em suas atividades profissionais.

Segundo Limongi-França e Rodrigues (2005), assim como a alimentação e o exercício físico, se estiverem dentro de determinado limites, são adequados e satisfatórios, portanto benéficos, o trabalho também pode ser fonte de satisfação, de realização pessoal e profissional. O trabalho, porém, pode tornar-se um sofrimento, mas este pode se transformar em ações criativas que modificam as exigências da vida no trabalho e criam espaços para uma Qualidade de Vida.

No campo organizacional há diversas medidas que podem ser adotadas. Mudanças exigem novas competências, que tem como função gerenciar todas as mudanças, surgindo, dessa maneira, a gestão de qualidade de vida no trabalho, como por exemplo: contatos sociais, treinamentos, melhorias no plano de cargos e salários.

O bem estar organizacional envolve a saúde emocional dos colaboradores, com o aprimoramento de ações e estratégias de Gestão da Qualidade de Vida no Trabalho, GQVT. O estresse é também característico de ambiente de trabalho, nos mais diversos 
níveis organizacionais.

Se faz necessário o apoio da direção da organização para manter constantes os programas de QVT em todos os níveis, pois pode consequentemente diminuir os custos com assistência médica, psicológica, absenteísmo e rotatividade. Com isso, o colaborador seguro e saudável mantém a assiduidade, produz mais e contribui de forma mais efetiva.

Segundo Limongi-França e Rodrigues (2005), a realidade gerencial da QVT no Brasil tem se mostrado, na prática, de forma parcial e incompleta. A atuação da qualidade voltada para as pessoas traz um referencial assistencialista, ou simplesmente as ações ignoram as políticas de qualidade de vida no trabalho. Sendo importante ressaltar que a QVT não pode ser confundida com a distribuição de benefícios e sim com a integridade do colaborador sendo, portanto, o equilíbrio entre a vida pessoal e a profissional.

Utilizando-se a visão biopsicossomática, Rossi, Quick e Perrewé (2009), construíram uma tabela com critérios e focos que podem ser operacionalizados para a construção de indicadores de Gestão de Qualidade de Vida no Trabalho- G-QVT:

\begin{tabular}{|c|c|}
\multicolumn{1}{c|}{ Quadro 1 - Indicadores empresariais de G-QVT } \\
\hline Critérios & Focos \\
\hline Organizacional & $\begin{array}{c}\text { Imagem, treinamento e desenvolvimento, processos e tecnologia, comitês de } \\
\text { decisão, ausência de burocracia, rotinas de pessoal. }\end{array}$ \\
\hline Biológico & $\begin{array}{c}\text { Semana interna de prevenção de acidentes, controle de riscos ergonômicos -PPRA, } \\
\text { ambulatório médico, ginástica laboral, refeições (refeitório), saúde -PCSMO, } \\
\text { comissão- CIPA }\end{array}$ \\
\hline Psicológico & $\begin{array}{c}\text { Recrutamento e seleção, avaliação do desempenho, camaradagem- clima } \\
\text { organizacional, carreira, salário, vida pessoal. }\end{array}$ \\
\hline Social & $\begin{array}{c}\text { Convênios comerciais, tempo livre - lazer, filhos, cesta básica, previdência privada, } \\
\text { financiamento de cursos. }\end{array}$ \\
\hline
\end{tabular}

Fonte: Rossi, Quick e Perrewé (2009, p. 270). Adaptação total.

Limongi-França (2004) afirma que a função da G-QVT é tentar unir todos os aspectos (benefícios, gestão de pessoas, ergonomia, balanço social, saúde, gestão de qualidade), de modo a consolidar atividades organizacionais relativas à QVT.

Todos esses aspectos demonstram a complexidade de administrar o bem-estar das pessoas, contando com a habilidade do gestor, o qual deve ter a capacidade de perceber sinais que evidenciem a falta de bem-estar e de qualidade de vida no trabalho.

A rápida transformação e as novas tecnologias ocorridas na sociedade nos últimos anos tem aumentado as exigências sobre o trabalho dos docentes, que também sofrem pela fragmentação da atividade e pelo aumento de responsabilidades exigidas e, em algumas situações, sem condições de responder adequadamente às novas demandas (ESTEVE, 1999).

Não há docência sem discência, as duas se explicam e seus sujeitos, apesar das diferenças que os conotam, não se reduzem à condição de objeto um do outro. Quem ensina aprende a ensinar e quem aprende também ensina ao aprender (FREIRE, 1996, p.12).

Na visão do autor, a prática do docente envolve mais do que simplesmente ensinar, pois ensinar requer vários fatores como: pesquisa, reflexão crítica sobre a prática e estudo, existindo, assim, a reciprocidade.

De acordo com Franco e Morisini (2001), no que diz respeito ao ensino superior brasileiro, o professor universitário caracteriza-se pela diversidade, pela pluralidade de opções, alternativas e interesses, pois na ótica institucional ele dispõe de horas de pesquisa e de ensino; na ótica política, vive as tensões na própria área do conhecimento e no corporativismo; na perspectiva profissional é permanentemente avaliado, seja nas avaliações sistemáticas, na submissão de trabalhos em eventos, na apresentação de projetos e de relatórios ou em pesquisas. 
O docente, enquanto profissional do ensino superior, deve estar em contínuo aperfeiçoamento, desenvolvendo, assim, suas habilidades cognitivas, mas sempre consciente de seus valores, pela finalidade de seu trabalho que é ensinar.

A criação do Sistema Nacional Avaliação da Educação Superior, SINAES, aprovado pela Lei no 10.861, de 2004 para analisar as Instituições de Ensino Superior em relação aos cursos e aos estudantes, requer dos docentes qualificação constante, produção científica e avaliação periódica pela sua competência.

Isto pode ocasionar determinados fatores de estresse no trabalho que, se persistirem, podem levar à exaustão ou à Síndrome de Burnout. Esta síndrome é definida por Harrison (1999) apud Carlotto (2002), como resultado de estresse crônico, devido ao cotidiano do trabalho, quando existe pressão, conflitos e pouca recompensa emocional.

\section{Metodologia}

A metodologia é o estudo de caso, do tipo descritiva; pesquisa classificada como exploratória tem o questionário como instrumento para a coleta de dados. A Pesquisa foi realizada para responder a alguns questionamentos relacionados à qualidade de vida no trabalho dos docentes de dois setores da Universidade Estadual do Centro Oeste, UNICENTRO.

O questionário é um instrumento adequado quando se quer acumular quantidade de dados. Foram elaborados os questionários na forma escala de Likert, em que apresenta-se ao respondente um conjunto de itens, em cada um dele, assinala-se uma resposta indicada à força de sua concordância ou discordância com a declaração inicial.

Os passos do processo de pesquisa apresentados por Gil (2006) foram seguidos em três fases: 1) pesquisa bibliográfica da conceitualização de qualidade de vida e qualidade de vida no trabalho; 2) aplicação de questionário aos docentes em atividades, sendo estes colaboradores e efetivos de dois setores (SESA e SEHLA), Campus Santa Cruz da UNICENTRO, sendo que, foram apresentados 70 questionários do SESA e 107 do SEHLA, num universo representado por 177 questionários aplicados, numa amostragem de $80,45 \%$ do total de docentes, do retorno de documentos entregues, com a margem amostral de erro de $5 \%$; 3) tabulação dos dados obtidos e fundamentação teórica; com algumas questões pertinentes ao assunto pesquisado. Buscou-se identificar o perfil dos entrevistados dos dois setores, o significado atribuído pelos docentes ativos à qualidade de vida, estudo exploratório, cujos dados foram tratados de forma quantitativa.

A pesquisa quantitativa caracteriza-se pelo emprego de instrumentos estatísticos, tanto na coleta quanto no tratamento de dados. Segundo Richardson (1999), ela destacase pela importância ao ter a intenção de garantir a precisão dos resultados e a obtenção de dados sobre as características de opinião de um determinado grupo de pessoas.

A primeira fase da pesquisa permitiu uma abordagem introdutória da formulação do problema, partindo da busca pela excelência na qualidade de vida no trabalho de dos docentes dos dois Setores do Campus Santa Cruz, que atuam em salas de aula e alguns em atividades administrativas no Ensino Superior. Segundo Moreno-Jimenes et al. (2002), os docentes são profissionais com riscos psicossociais, pois estes tem dentro da organização fatores que podem desencadear o estresse e também com situações nas quais desequilibram as expectativas individuais do profissional e a realidade do trabalho. Assim é relevante a investigação daquilo que interfere na qualidade de vida no dos docentes universitários e fatores associados ao seu trabalho.

A segunda fase partiu do entendimento de uma pesquisa exploratória uma investigação por meio de estudo de caso. Nesta etapa foram elencadas questões que foram pertinentes ao estudo de caso. O questionário foi aplicado aos docentes que se encontravam nas reuniões de departamentos, no período de quarenta dias. As questões foram a tradução dos objetivos previstos na fase anterior, sendo 41 questões, 
organizadas entre 40 respostas fechadas e uma aberta. Ainda, segundo Gil (2006), as respostas precisam proporcionar dados para a descrição das características ou para testar as hipóteses construídas, sendo assim, a elaboração do questionário se tornou, nesta pesquisa, um procedimento eficaz na elaboração e análise dos resultados.

Após a obtenção dos dados, a terceira fase foi de tabulação dos dados obtidos, dispondo-os em tabelas e gráfico, possibilitando uma melhor visualização dos resultados. Por fim, a compreensão da construção dos dados obtidos e pela observação baseada em bibliografia, foram feitas a interpretação e análise dos dados.

\section{Análises dos resultados}

Este item apresenta os resultados da coleta de dados e análises correspondentes. A pesquisa sobre qualidade de vida dos docentes pode ser considerada uma abordagem do estudo da qualidade de vida e vem recebendo atenção crescente de pesquisadores de diversas áreas de conhecimentos como na saúde, psicologia, economia, administração e engenharias.

O artigo $6^{\circ}$ da Constituição Federal, de 1988, refere-se aos direitos sociais de forma genérica do ser humano, como o direito à saúde, ao trabalho, ao lazer entre outros, partindo desse pressuposto os direitos sociais buscam a qualidade de vida dos indivíduos.

Com a observação baseada na questão bibliográfica, foram feitas as interpretações e análises de dados.

\section{1. Análise dos questionários}

Considerando o contexto atual e a demanda de trabalhos desenvolvidos pelos docentes, visamos à melhoria da qualidade do trabalho e do desenvolvimento humano, incentivando o comprometimento e a responsabilidade dos docentes no desempenho de suas atividades.

Pretendeu-se verificar, por meio de pesquisa exploratória, a satisfação ou a insatisfação dos docentes dos dois setores da Instituição. Quanto à sua natureza, a pesquisa foi aplicada e a sua abordagem foi quantitativa e descritiva por meio de estudo de caso. Para a coleta de dados, foram utilizados os instrumentos de pesquisa bibliográfica, aplicação de questionários, tabulação dos dados obtidos e a análise.

No primeiro item, foram propostos questionamentos a respeito do significado de qualidade de vida no trabalho para cada respondente. Numa ordem de importância, direcionados com respostas fechadas, em primeiro plano resultou o item relacionado à área psicológica (realização pessoal) com percentual de 36\% dos respondentes do setor SEHLA e 24\% do setor SESA; o item confiança (área social) resultou em segundo plano, com $20 \%$ setor SEHLA e $15 \%$ setor SESA; e terceiro plano correspondeu ao item também relacionado à área social (responsabilidade), 24\% setor SEHLA e 13\% setor SESA.

Tabela 1: Perfil dos Professores Pesquisados

\begin{tabular}{|c|c|c|}
\hline Variável & Professores SESA & Professores SEHLA \\
\hline 01. SEXO: & $\begin{array}{l}60 \% \text { Masculino } \\
40 \% \text { Feminino }\end{array}$ & $\begin{array}{l}32 \% \text { Masculino } \\
68 \% \text { Feminino }\end{array}$ \\
\hline 02. IDADE: & $\begin{array}{l}\text { (9) até } 30 \text { anos (13) } 31 \text { a } 35 \\
\text { anos (15) } 36 \text { a } 40 \text { anos }\end{array}$ & $\begin{array}{c}\text { (10) até } 30 \text { anos (18) } 31 \text { a } 35 \\
\text { anos (23) } 36 \text { a 40anos }\end{array}$ \\
\hline & $\begin{array}{l}\text { (14) } 41 \text { a } 45 \text { anos (7) } 46 \text { a } 50 \\
\text { anos (12) acima de } 50 \text { anos }\end{array}$ & $\begin{array}{l}\text { (21) } 41 \text { a } 45 \text { anos (12) } 46 \text { a } 50 \\
\text { anos (23) acima de } 50 \text { anos }\end{array}$ \\
\hline
\end{tabular}


03. ESCOLARIDADE:

04. HÁ QUANTO TEMPO LECIONA:

05. SETOR DO SEU DEPTO:

06. ESTADO CIVIL:

\section{EM QUANTAS TURMAS LECIONA}

(18) Especialista (44) Mestre

(8) Doutor(a)

( ) Outro. Qual?

(20) de 1 a 5 anos (23) de

6 a 10 anos (27) mais de 10 anos

70 SESA/G

(51) Casado (a)

(12)

Solteiro (a) (7) Divorciado (a) ( ) Outro

(4) 1 turma (13) 2 turmas
(23) 3 turmas (4) 4 turmas

(16) 5 ou mais

08. QUANTAS HORAS SEMANAIS EM SALA DE AULA

09. QUANTAS HORAS DEDICA-SE AS ATIVIDADES ADMINISTRATIVAS
(29) até 9 horas horas

(10) até 16 horas

(15) até 20 horas

(19) Não tenho atividades administrativas
(8) até 5 horas
(6) até 10
horas
(5) até 15 horas

(19) até 20 horas (13) acima 20 horas
(11) Especialista (47) Mestre (46) Doutor (a)

(3) Outro. Qual? Pós-doutorado

(24) de 1 a 5 anos (22) de 6 a 10 anos (61) mais de 10 anos

107 SEHLA/G

(74) Casado (a) (15) Solteiro

(a) (11) Divorciado (a) (7) Outro

(1) 1 turma (14) 2 turmas (42) 3 turmas (21) 4 turmas

(29) 5 ou mais

(47) até 9 horas (18) até 12 horas (17) até 16 horas

(25) até 20 horas

(47) Não tenho atividades administrativas

(16) até 5 horas (7) até 10

horas (0) até 15 horas

(14) até 20 horas (23) acima 20 horas

Fonte: Pesquisa de campo, 2013.

A tabela 1 apresenta os dados demográficos dos professores pesquisados dos dois setores. No SESA, os homens são a maioria, enquanto que no SEHLA, são as mulheres, que é próprio das áreas de conhecimentos, pois os cursos do SESA são de bacharelados e do SEHLA são licenciaturas, que trabalham mais com professoras. As diferenciações estão na faixa etária a maioria dos docentes SESA tem entre 36 a 40 anos, e do SEHLA tem acima dos 50 . Dado relevante no que diz respeito à escolaridade, pois um número significativo de docentes com a titulação doutor estão na licenciatura (43\%), enquanto que somente $11 \%$ estão atuando no bacharelado, isto deve provavelmente ao fato dos docentes do SEHLA dedicarem maior tempo nas atividades da Instituição. Um número equilibrado entre os dois setores foi o fato de não atividades administrativas, porém, o setor SEHLA possui um número significativo de docentes que trabalham acima de 20 horas nas atividades administrativas. Isto supõe que os docentes de licenciaturas permanecem maior tempo na Instituição, isto é, tempo dedicação exclusiva.

Tabela 2 - Saúde X Doenças nos últimos 12 meses

\begin{tabular}{|c|c|c|c|c|c|c|c|c|}
\hline Variável & & SES & & & & SEF & HLA & \\
\hline $\begin{array}{l}\text { Ocorrências de saúde-doença nos últimos } 12 \\
\text { meses? }\end{array}$ & Não & $\%$ & Sim & $\%$ & Não & $\%$ & Sim & $\%$ \\
\hline 2. Utilizou remédios para dores específicas? & 27 & $39 \%$ & 43 & $61 \%$ & 42 & $39 \%$ & 65 & $61 \%$ \\
\hline 3. Sofreu internação em hospital? & 64 & $91 \%$ & 6 & $9 \%$ & 90 & $84 \%$ & 17 & $16 \%$ \\
\hline
\end{tabular}




\begin{tabular}{lllllllll}
\hline 4. Foi atendido em pronto-socorro & 56 & $80 \%$ & 14 & $20 \%$ & 77 & $72 \%$ & 30 & $28 \%$ \\
5. Utilizou o convênio médico ou SAS ou SUS & 51 & $73 \%$ & 19 & $27 \%$ & 64 & $60 \%$ & 43 & $40 \%$ \\
6. Faltou ao trabalho por mal-estar ou doença? & 54 & $77 \%$ & 16 & $23 \%$ & 70 & $65 \%$ & 37 & $35 \%$ \\
\hline
\end{tabular}

Fonte: Pesquisa de campo, 2013.

São apresentados, na tabela 2, os resultados da pesquisa das ocorrências de saúde-doença dos docentes SESA e SEHLA, sendo que há uma incidência grande quanto na utilização de medicamentos dos docentes dos dois setores (61\%) citados por vários fatores, tais como: dores de cabeça, enxaqueca e dor na coluna, isto deve-se provavelmente as excessivas funções, condições ambientais de trabalho e quando estes sintomas são reconhecidos, as pessoas tendem a buscar medicações por conta própria. Nota-se que não há problema de absenteísmo, pois há uma baixa incidência em internação hospitalar, atendimento em pronto socorro e utilização de convênios médicos.

A seguir, apresenta-se quatro quadros com os resultados das avaliações dos aspectos: organizacionais, biológicos, psicológicos e sociais, de acordo com os docentes pesquisados.

Tabela 3 - Concordância em relação as variáveis de Aspectos Organizacionais (em \%):

\begin{tabular}{|c|c|c|c|c|c|c|c|c|c|c|c|c|c|c|c|c|c|c|c|c|c|c|}
\hline \multirow[b]{2}{*}{ Variáveis } & \multicolumn{15}{|c|}{ SESA } & \multicolumn{7}{|c|}{ SEHLA } \\
\hline & 1 & $\%$ & 2 & $\%$ & 3 & $\%$ & 4 & $\%$ & NT & $\%$ & MÉDIA & 1 & $\%$ & 2 & $\%$ & 3 & $\%$ & 4 & $\%$ & NT & $\%$ & $\begin{array}{l}\text { MÉD } \\
\text { IA }\end{array}$ \\
\hline $\begin{array}{l}\text { 7. Imagem da } \\
\text { empresa junto } \\
\text { aos professores } \\
\text { (as). }\end{array}$ & 4 & $6 \%$ & 5 & $7 \%$ & 30 & $43 \%$ & 30 & $43 \%$ & 1 & $1 \%$ & 3,2 & 4 & $4 \%$ & 14 & $13 \%$ & 62 & $58 \%$ & 21 & $20 \%$ & 6 & $6 \%$ & 2,8 \\
\hline $\begin{array}{l}\text { 8. Oportunidade } \\
\text { de treinamento e } \\
\text { desenvolvimento } \\
\text { profissional. }\end{array}$ & 9 & $13 \%$ & 12 & $17 \%$ & 28 & $40 \%$ & 17 & $24 \%$ & 4 & $6 \%$ & 2,6 & 8 & $7 \%$ & 16 & $15 \%$ & 52 & $49 \%$ & 24 & $22 \%$ & 7 & $7 \%$ & 2,7 \\
\hline $\begin{array}{l}\text { 9. Melhorias nos } \\
\text { processos de } \\
\text { trabalho e novas } \\
\text { tecnologias. }\end{array}$ & 5 & $7 \%$ & 12 & $17 \%$ & 42 & $60 \%$ & 10 & $14 \%$ & 1 & $1 \%$ & 2,8 & 8 & $7 \%$ & 23 & $21 \%$ & 59 & $55 \%$ & 15 & $14 \%$ & 2 & $2 \%$ & 2,7 \\
\hline $\begin{array}{l}10 \text { Oportunidade } \\
\text { de participar de } \\
\text { comitês de } \\
\text { decisão. }\end{array}$ & 6 & $9 \%$ & 17 & $24 \%$ & 35 & $50 \%$ & 10 & $14 \%$ & 2 & $3 \%$ & 2,6 & 5 & $5 \%$ & 10 & $9 \%$ & 56 & $52 \%$ & 30 & $28 \%$ & 6 & $6 \%$ & 2,9 \\
\hline $\begin{array}{l}\text { 11. Qualidade } \\
\text { dos } \\
\text { procedimentos } \\
\text { administrativos. }\end{array}$ & 7 & $10 \%$ & 8 & $11 \%$ & 30 & $43 \%$ & 23 & $33 \%$ & 2 & $3 \%$ & 2,9 & 7 & $7 \%$ & 23 & $21 \%$ & 57 & $53 \%$ & 18 & $17 \%$ & 2 & $2 \%$ & 2,8 \\
\hline $\begin{array}{l}\text { 12. Atendimento } \\
\text { às rotinas de } \\
\text { pessoal (registro, } \\
\text { documentos,etc.). }\end{array}$ & 5 & $7 \%$ & 5 & $7 \%$ & 25 & $36 \%$ & 33 & $47 \%$ & 2 & $3 \%$ & 3,2 & 4 & $4 \%$ & 19 & $18 \%$ & 57 & $53 \%$ & 25 & $23 \%$ & 2 & $2 \%$ & 2,9 \\
\hline $\begin{array}{l}\text { 13. Incentivo a } \\
\text { produção } \\
\text { científica. }\end{array}$ & 5 & $7 \%$ & 5 & $7 \%$ & 36 & $51 \%$ & 23 & $33 \%$ & 1 & $1 \%$ & 3,1 & 5 & $5 \%$ & 19 & $18 \%$ & 43 & $40 \%$ & 38 & $36 \%$ & 2 & $2 \%$ & 3,0 \\
\hline $\begin{array}{l}14 \text { Qualidade dos } \\
\text { equipamentos. }\end{array}$ & 1 & $1 \%$ & 10 & $14 \%$ & 32 & $46 \%$ & 27 & $39 \%$ & 0 & $0 \%$ & 3,2 & 2 & $2 \%$ & 22 & $21 \%$ & 56 & $52 \%$ & 27 & $25 \%$ & 0 & $0 \%$ & 3,0 \\
\hline $\begin{array}{l}\text { 15. Quantidade } \\
\text { dos } \\
\text { equipamentos. }\end{array}$ & 4 & $6 \%$ & 8 & $11 \%$ & 30 & $43 \%$ & 28 & $40 \%$ & 0 & $0 \%$ & 3,2 & 4 & $4 \%$ & 15 & $14 \%$ & 54 & $50 \%$ & 31 & $29 \%$ & 3 & $3 \%$ & 3,0 \\
\hline $\begin{array}{l}16 \text { Biblioteca } \\
\text { (número de livros } \\
\text { e revistas para a } \\
\text { sua disciplina). }\end{array}$ & 10 & $14 \%$ & 24 & $34 \%$ & 26 & $37 \%$ & 10 & $14 \%$ & 0 & $0 \%$ & 2,5 & 18 & $17 \%$ & 37 & $35 \%$ & 40 & $37 \%$ & 10 & $9 \%$ & 2 & $2 \%$ & 2,4 \\
\hline
\end{tabular}




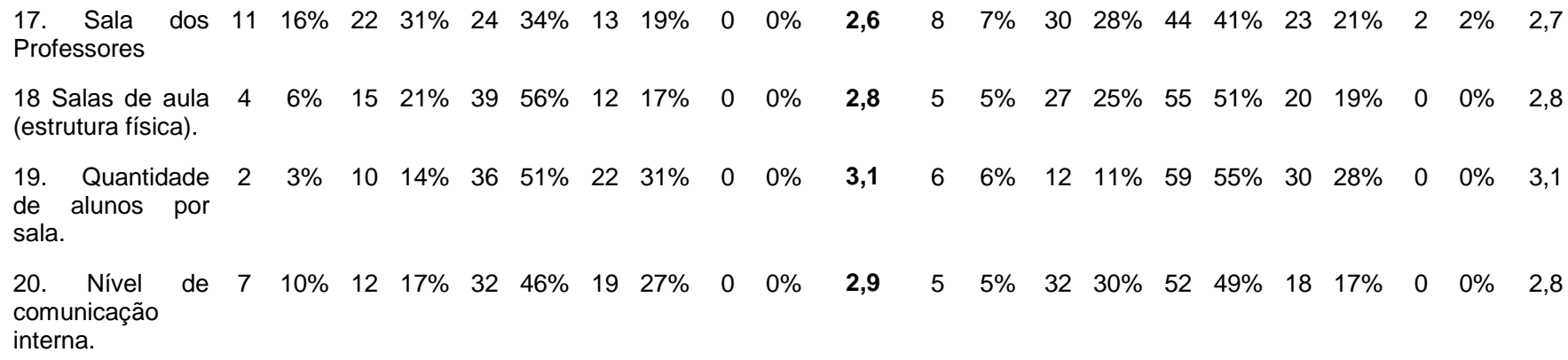

Fonte: Pesquisa de campo, 2013

A tabela 3 apresenta os resultados da satisfação dos docentes em relação às variáveis organizacionais. Pode-se observar que o setor SESA $(3,2)$ em relação ao setor SEHLA (2,8), possui médias superiores no que diz respeito à imagem da Instituição, e quanto ao atendimento à rotina de pessoal. Porém, equivalem quanto à quantidade $\mathrm{e}$ qualidade de equipamentos na satisfação, quantidade de alunos por sala e, também, equivalem nos itens biblioteca, sala de professores e oportunidades de participação em comitês que têm uma menor satisfação. Concluindo-se que os dois setores estão parcialmente satisfeitos em relação aos aspectos organizacionais.

Tabela 4 - Concordância em relação as variáveis de Aspectos Biológicos (em \%):

\begin{tabular}{|c|c|c|c|c|c|c|c|c|c|c|c|c|c|c|c|c|c|c|c|c|c|c|}
\hline \multirow[b]{2}{*}{ Variáveis } & \multicolumn{11}{|c|}{ SESA } & \multicolumn{11}{|c|}{ SEHLA } \\
\hline & 1 & $\%$ & 2 & $\%$ & 3 & $\%$ & 4 & $\%$ & $\begin{array}{l}\mathbf{N} \\
\mathbf{T}\end{array}$ & $\%$ & MÉDIA & 1 & $\%$ & 2 & $\%$ & 3 & $\%$ & $4 \%$ & $\%$ & $\begin{array}{l}\mathbf{N} \\
\mathbf{T}\end{array}$ & $\%$ & $\begin{array}{c}\text { MÉDI } \\
\text { A }\end{array}$ \\
\hline $\begin{array}{l}\text { 21. Controle } \\
\text { dos riscos } \\
\text { ergonômicos }\end{array}$ & 8 & $\begin{array}{l}11 \\
\%\end{array}$ & $\begin{array}{l}2 \\
5\end{array}$ & $\begin{array}{l}36 \\
\%\end{array}$ & $\begin{array}{l}1 \\
9\end{array}$ & $\begin{array}{l}27 \\
\%\end{array}$ & $\begin{array}{l}1 \\
1\end{array}$ & $\begin{array}{l}16 \\
\%\end{array}$ & 7 & $\begin{array}{l}10 \\
\%\end{array}$ & 2,3 & $\begin{array}{l}1 \\
6\end{array}$ & $\begin{array}{l}15 \\
\%\end{array}$ & $\begin{array}{l}2 \\
7\end{array}$ & $\begin{array}{l}25 \\
\%\end{array}$ & $\begin{array}{l}3 \\
3\end{array}$ & $\begin{array}{l}31 \\
\%\end{array}$ & 9 & $\begin{array}{l}8 \\
\%\end{array}$ & $\begin{array}{ll}2 & 2 \\
2 & 9\end{array}$ & $\begin{array}{l}21 \\
\%\end{array}$ & 1,9 \\
\hline $\begin{array}{l}22 . \\
\text { Atendimento } \\
\text { do convênio } \\
\text { médico }\end{array}$ & 9 & $\begin{array}{l}13 \\
\%\end{array}$ & $\begin{array}{l}1 \\
1\end{array}$ & $\begin{array}{l}16 \\
\%\end{array}$ & $\begin{array}{l}2 \\
0\end{array}$ & $\begin{array}{l}29 \\
\%\end{array}$ & $\begin{array}{l}1 \\
4\end{array}$ & $\begin{array}{l}20 \\
\%\end{array}$ & $\begin{array}{l}1 \\
6\end{array}$ & $\begin{array}{l}23 \\
\%\end{array}$ & 2,1 & $\begin{array}{l}2 \\
0\end{array}$ & $\begin{array}{l}19 \\
\%\end{array}$ & $\begin{array}{l}1 \\
6\end{array}$ & $\begin{array}{l}15 \\
\%\end{array}$ & $\begin{array}{l}3 \\
6\end{array}$ & $\begin{array}{l}34 \\
\%\end{array}$ & $\begin{array}{ll}1 & 1 \\
4 & 0\end{array}$ & $\begin{array}{l}13 \\
\%\end{array}$ & $\begin{array}{ll}2 & 2 \\
1 & 9\end{array}$ & $\begin{array}{l}20 \\
\%\end{array}$ & 2,0 \\
\hline $\begin{array}{l}\text { 23. Estado } \\
\text { geral de saúde } \\
\text { dos colegas e } \\
\text { superiores }\end{array}$ & 1 & $\begin{array}{c}1 \\
\%\end{array}$ & 6 & $\begin{array}{c}9 \\
\%\end{array}$ & $\begin{array}{l}3 \\
6\end{array}$ & $\begin{array}{l}51 \\
\%\end{array}$ & $\begin{array}{l}1 \\
5\end{array}$ & $\begin{array}{l}21 \\
\%\end{array}$ & $\begin{array}{l}1 \\
2\end{array}$ & $\begin{array}{l}17 \\
\%\end{array}$ & 2,6 & 6 & $\begin{array}{c}6 \\
\%\end{array}$ & $\begin{array}{l}2 \\
4\end{array}$ & $\begin{array}{l}22 \\
\%\end{array}$ & $\begin{array}{l}3 \\
7\end{array}$ & $\begin{array}{l}35 \\
\%\end{array}$ & $\begin{array}{ll}1 & 1 \\
2 & 0\end{array}$ & $\begin{array}{l}11 \\
\%\end{array}$ & $\begin{array}{ll}2 & 2 \\
8 & 9\end{array}$ & $\begin{array}{l}26 \\
\%\end{array}$ & 2,0 \\
\hline $\begin{array}{l}\text { 24. Qualidade } \\
\text { dos programas } \\
\text { de prevenção } \\
\text { de doencas }\end{array}$ & $\begin{array}{l}1 \\
0\end{array}$ & $\begin{array}{l}14 \\
\%\end{array}$ & $\begin{array}{l}2 \\
1\end{array}$ & $\begin{array}{l}30 \\
\%\end{array}$ & $\begin{array}{l}1 \\
8\end{array}$ & $\begin{array}{l}26 \\
\%\end{array}$ & 9 & $\begin{array}{l}13 \\
\%\end{array}$ & $\begin{array}{l}1 \\
2\end{array}$ & $\begin{array}{l}17 \\
\%\end{array}$ & 2,0 & $\begin{array}{l}1 \\
4\end{array}$ & $\begin{array}{l}13 \\
\%\end{array}$ & $\begin{array}{l}2 \\
6\end{array}$ & $\begin{array}{l}24 \\
\%\end{array}$ & $\begin{array}{l}2 \\
9\end{array}$ & $\begin{array}{l}27 \\
\%\end{array}$ & $\begin{array}{l}1 \\
0\end{array}$ & $\begin{array}{c}9 \\
\%\end{array}$ & $\begin{array}{ll}2 & 2 \\
8 & 9\end{array}$ & $\begin{array}{l}26 \\
\%\end{array}$ & 1,8 \\
\hline
\end{tabular}

Fonte: Pesquisa de campo, 2013.

A tabela 4 apresenta os resultados da satisfação dos docentes em relação aos aspectos biológicos, que foram os mais críticos. Ou eles não tinham opinião formada sobre os itens abordados, ou estavam insatisfeitos com a qualidade dos serviços, programas de prevenção de doenças e atendimento do convênio médico. A média dos dois setores é a insatisfação parcial, que pode ser decorrente de falta de investimento em programas relacionados à saúde e, também, à falta de informação da Instituição sobre as ações realizadas referentes a essas variáveis. 
Tabela 5 - Concordância em relação as variáveis de Aspectos Psicológicos (em \%):

\begin{tabular}{|c|c|c|c|c|c|c|c|c|c|c|c|c|c|c|c|c|c|c|c|c|c|c|}
\hline \multirow[b]{2}{*}{ Variáveis } & \multicolumn{11}{|c|}{ SESA } & \multicolumn{11}{|c|}{ SEHLA } \\
\hline & 1 & $\%$ & 2 & $\%$ & 3 & $\%$ & 4 & $\%$ & NT & $\%$ & MÉDIA & 1 & $\%$ & 2 & $\%$ & 3 & $\%$ & 4 & $\%$ & NT & $\%$ & MÉDIA \\
\hline $\begin{array}{l}\text { 25. Confiança nos } \\
\text { critérios de } \\
\text { recrutamento e } \\
\text { seleção }\end{array}$ & 8 & $11 \%$ & 10 & $14 \%$ & 25 & $36 \%$ & 24 & $34 \%$ & 3 & $4 \%$ & 2,8 & 7 & $7 \%$ & 20 & $19 \%$ & 50 & $47 \%$ & 30 & $28 \%$ & 0 & $0 \%$ & 3,0 \\
\hline $\begin{array}{l}\text { 26. Forma de } \\
\text { avaliação do } \\
\text { desempenho do } \\
\text { seu trabalho }\end{array}$ & 5 & $7 \%$ & 16 & $23 \%$ & 28 & $40 \%$ & 16 & $23 \%$ & 5 & $7 \%$ & 2,6 & 10 & $9 \%$ & 25 & $23 \%$ & 47 & $44 \%$ & 16 & $15 \%$ & 9 & $8 \%$ & 2,5 \\
\hline $\begin{array}{l}\text { 27. Clima de } \\
\text { camaradagem entre } \\
\text { as pessoas }\end{array}$ & 7 & $10 \%$ & 9 & $13 \%$ & 32 & $46 \%$ & 21 & $30 \%$ & 1 & $1 \%$ & 2,9 & 7 & $7 \%$ & 29 & $27 \%$ & 48 & $45 \%$ & 17 & $16 \%$ & 6 & $6 \%$ & 2,6 \\
\hline $\begin{array}{l}\text { 28. Oportunidade } \\
\text { de carreira }\end{array}$ & 8 & $11 \%$ & 5 & $7 \%$ & 29 & $41 \%$ & 25 & $36 \%$ & 3 & $4 \%$ & 2,9 & 8 & $7 \%$ & 15 & $14 \%$ & 52 & $49 \%$ & 29 & $27 \%$ & 3 & $3 \%$ & 2,9 \\
\hline $\begin{array}{l}\text { 29. Satisfação com } \\
\text { o salário }\end{array}$ & 9 & $13 \%$ & 18 & $26 \%$ & 31 & $44 \%$ & 12 & $17 \%$ & 0 & $0 \%$ & 2,7 & 17 & $16 \%$ & 28 & $26 \%$ & 48 & $45 \%$ & 14 & $13 \%$ & 0 & $0 \%$ & 2,6 \\
\hline
\end{tabular}

Fonte: Pesquisa de campo, 2013.

$\mathrm{Na}$ tabela 5 observa-se as médias de avaliações referentes aos aspectos psicológicos. Os pesquisados são parcialmente satisfatórios devido às variáveis: confiança nos critérios de recrutamento e seleção de professores/ líderes/ coordenadores (concursos, testes, eleições) e à oportunidade de carreira. As menores médias são referentes à forma de avaliação do desempenho do trabalho e satisfação do salário, que pode ser decorrente das dificuldades das universidades públicas em gerar recursos e condições de trabalho condizentes com a atuação do docente, para uma avaliação mais eficaz.

Tabela 6 - Concordância em relação às variáveis de Aspectos Sociais (em \%):

\begin{tabular}{|c|c|c|c|c|c|c|c|c|c|c|c|c|c|c|c|c|c|c|c|c|c|c|}
\hline \multirow[b]{2}{*}{ Variáveis } & \multicolumn{11}{|c|}{ SESA } & \multicolumn{11}{|c|}{ SEHLA } \\
\hline & 1 & $\%$ & 2 & $\%$ & 3 & $\%$ & 4 & $\%$ & $\begin{array}{l}\mathrm{N} \\
\mathrm{T}\end{array}$ & $\%$ & MÉDIA & 1 & $\%$ & 2 & $\%$ & 3 & $\%$ & 4 & $\%$ & $\begin{array}{l}\mathrm{N} \\
\mathrm{T}\end{array}$ & $\%$ & $\begin{array}{l}\text { MÉ } \\
\text { DIA }\end{array}$ \\
\hline $\begin{array}{c}30 . \\
\text { Qualidade } \\
\text { de } \\
\text { convênios } \\
\text { (médico) }\end{array}$ & 8 & $\begin{array}{l}11 \\
\%\end{array}$ & $\begin{array}{l}1 \\
2\end{array}$ & $\begin{array}{l}17 \\
\%\end{array}$ & $\begin{array}{l}2 \\
1\end{array}$ & $\begin{array}{l}30 \\
\%\end{array}$ & $\begin{array}{l}1 \\
4\end{array}$ & $\begin{array}{l}20 \\
\%\end{array}$ & $\begin{array}{l}1 \\
5\end{array}$ & $\begin{array}{l}21 \\
\%\end{array}$ & 2,2 & $\begin{array}{l}2 \\
4\end{array}$ & $\begin{array}{l}2 \\
2 \\
\%\end{array}$ & $\begin{array}{l}1 \\
3\end{array}$ & $\begin{array}{l}12 \\
\%\end{array}$ & $\begin{array}{l}2 \\
7\end{array}$ & $\begin{array}{l}25 \\
\%\end{array}$ & $\begin{array}{l}1 \\
4\end{array}$ & $\begin{array}{l}13 \\
\%\end{array}$ & $\begin{array}{l}2 \\
9\end{array}$ & $\begin{array}{l}27 \\
\%\end{array}$ & 1,7 \\
\hline $\begin{array}{c}31 . \\
\text { Oportunidad } \\
\text { e para } \\
\text { distração }\end{array}$ & 5 & $\begin{array}{l}7 \\
\%\end{array}$ & $\begin{array}{l}1 \\
4\end{array}$ & $\begin{array}{l}20 \\
\%\end{array}$ & $\begin{array}{l}2 \\
5\end{array}$ & $\begin{array}{l}36 \\
\%\end{array}$ & $\begin{array}{l}1 \\
2\end{array}$ & $\begin{array}{l}17 \\
\%\end{array}$ & $\begin{array}{l}1 \\
4\end{array}$ & $\begin{array}{l}20 \\
\%\end{array}$ & 2,2 & $\begin{array}{l}1 \\
8\end{array}$ & $\begin{array}{l}1 \\
7 \\
\%\end{array}$ & $\begin{array}{l}3 \\
0\end{array}$ & $\begin{array}{l}28 \\
\%\end{array}$ & $\begin{array}{l}3 \\
0\end{array}$ & $\begin{array}{l}28 \\
\%\end{array}$ & 9 & $\begin{array}{l}8 \\
\%\end{array}$ & $\begin{array}{l}2 \\
0\end{array}$ & $\begin{array}{l}19 \\
\%\end{array}$ & 1,9 \\
\hline $\begin{array}{c}\text { 32. Bolsas e } \\
\text { auxílios para } \\
\text { cursos } \\
\text { externos }\end{array}$ & 9 & $\begin{array}{l}13 \\
\%\end{array}$ & $\begin{array}{l}2 \\
0\end{array}$ & $\begin{array}{l}29 \\
\%\end{array}$ & $\begin{array}{l}2 \\
0\end{array}$ & $\begin{array}{l}29 \\
\%\end{array}$ & $\begin{array}{l}1 \\
1\end{array}$ & $\begin{array}{l}16 \\
\%\end{array}$ & $\begin{array}{l}1 \\
0\end{array}$ & $\begin{array}{l}14 \\
\%\end{array}$ & 2,2 & $\begin{array}{l}1 \\
8\end{array}$ & $\begin{array}{l}1 \\
7 \\
\%\end{array}$ & $\begin{array}{l}2 \\
6\end{array}$ & $\begin{array}{l}24 \\
\%\end{array}$ & $\begin{array}{l}3 \\
6\end{array}$ & $\begin{array}{l}34 \\
\%\end{array}$ & $\begin{array}{l}1 \\
6\end{array}$ & $\begin{array}{l}15 \\
\%\end{array}$ & $\begin{array}{l}1 \\
1\end{array}$ & $\begin{array}{l}10 \\
\%\end{array}$ & 2,3 \\
\hline
\end{tabular}

Fonte: Pesquisa de campo, 2013.

A tabela 6 apresenta os resultados da avaliação dos aspectos sociais. Nela observa-se as médias de avaliação insatisfeita dos pesquisados, sendo a média geral de $(2,2)$ no setor SESA e de $(1,9)$ no setor SEHLA. Um número significativo de docentes que não tem opinião, pois a média geral é maior do que a média dos parcialmente satisfeitos. Pode-se observar, então, que a Instituição não conscientiza sobre as ações de uma forma profícua e, também, incentiva pouco os programas sociais, tais como: áreas de lazer, bolsas e auxílio para cursos externos. 
Figura 2: Avaliação dos Aspectos Biopsicossociais e Organizacionais

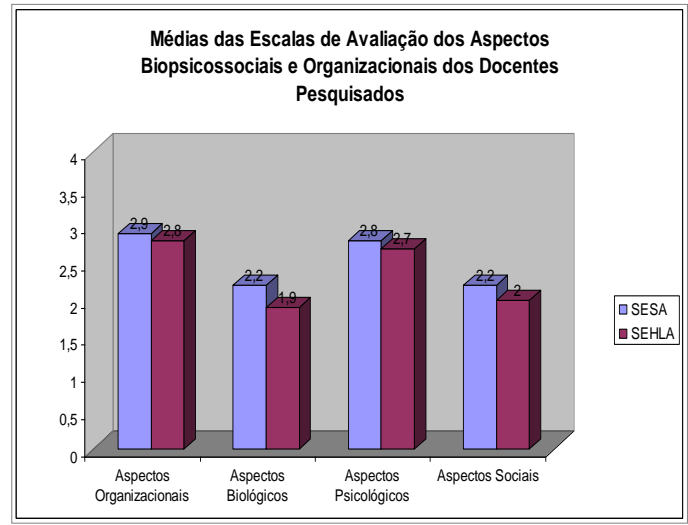

Fonte: Pesquisa de campo, 2013.

A figura 2 apresenta uma síntese das médias das escalas de avaliações, dos aspectos biopsicossociais e organizacionais que apontam, de acordo com os docentes pesquisados dos setores SESA e SEHLA, uma insatisfação parcial nas variáveis analisadas, pois a escala utilizada no questionário possui quatro categorias de escolha, variando da insatisfação total (1) à satisfação total (4). Apresentando-se média geral inferior aos níveis de satisfação parcial.

\section{Considerações finais}

O presente artigo objetivou analisar a satisfação dos docentes universitários, de cursos de bacharelado e licenciatura, da Universidade Estadual do Centro-Oeste, diante dos indicadores biopsicossociais e organizacionais de qualidade de vida no trabalho.

No aspecto ocorrência de saúde-doenças, nota-se que não há absenteísmo, pois continuam exercendo as atividades normalmente, apenas apresentam sintomas de dores de cabeça, coluna e enxaqueca, devido às excessivas funções e, quando estes sintomas são reconhecidos, são realizadas automedicações.

No que diz respeito aos aspectos organizacionais, nota-se que os dois setores pesquisados apresentam médias de satisfação superior em se tratando da imagem da Instituição. Em relação à qualidade e à quantidade de materiais na biblioteca, tem uma menor satisfação. Deve-se a isso, o pouco investimento da Instituição aos materiais didáticos (livros, revistas, DVD's).

Nos aspectos biológicos, as médias de avaliação dos pesquisados dos dois setores apresentam insatisfação parcial, devendo-se ao pouco investimento em programas relacionados à saúde, bem como a informação sobre as ações já realizadas, pois os pesquisados não tinham opinião sobre os itens questionados.

Nos aspectos psicológicos, o resultado foi parcialmente satisfeito, sendo as variáveis referentes a salários e à forma de avaliação de desempenho, a média correspondente a essas variáveis ficou abaixo da média parcial de satisfação.

Nos aspectos sociais, resultado da avaliação, as médias estão mais próximas da insatisfação parcial dos pesquisados. Entre todos os aspectos analisados, são as médias mais baixas de todas as variáveis questionadas, levando a crer que a Instituição está investindo muito pouco nessa área e que não possui uma política estruturada voltada ao bem estar e à satisfação das necessidades no tocante à qualidade de vida no trabalho.

Quanto ao significado de Qualidade de Vida no Trabalho, para os docentes dos dois setores, estaria ele associado dentro da área psicológica (realização pessoal) e da área social (confiança e a responsabilidade).

Este estudo auxiliará os docentes universitários a terem conhecimento do nível de satisfação de qualidade de vida no trabalho e às melhorias pelos administradores da 
Instituição, pois a melhor qualidade de vida no trabalho auxilia e melhora o crescimento do trabalhador, juntamente com o crescimento da organização.

Ressalta-se que esta pesquisa não pode ser a única resposta, e sim a importância de se aplicar a pesquisa nessa linha, nos Campi Cedeteg e Irati, como forma de comparar as diferenças setoriais, bem como o incentivo para a promoção de programas de qualidade de vida no trabalho. Incorporando desta forma, o tema qualidade de vida no trabalho na vida pessoal e profissional dos colaboradores da UNICENTRO.

\section{Referências}

AZEVEDO, V. A. A.; KITAMURA, S. Stress, trabalho e qualidade de vida. In: VILARTA, R. et. al. (Org.). Qualidade de vida e fadiga institucional. Campinas: IPES Editorial, 2006.

BALLONE, G. J.; PEREIRA, E. N.; ORTOLANI, I. V. Da emoção à Lesão: um Guia de Medicina Psicossomática. São Paulo: Manole, 2002.

BRASIL. Lei n. 10.861 de 14 de abril de 2004. Sistema Nacional de Avaliação da Educação superior (SINAES). Disponível em: <http://portal.inep.gov.br/superior-sinaes>. Acesso em: 25 abr. 2015

CARLOTTO, M. S. A Síndrome de Burnout e o Trabalho Docente. Psicologia em Estudo, Maringá, v. 7, n. 1, p. 21-29, jan./jun. 2002.

CID 10. Classificação Estatística Internacional de Doenças e Problemas Relacionados à Saúde. Centro Colaborador da OMS para a Classificação de Doenças em Português (CBCD). Décima Revisão, Versão 2008, Volume I. Disponível em: <http://www.datasus.gov.br/cid10/v2008/cid10.htm>. Acesso em: 28 mar. 2016.

ESTEVE, J. M. O mal-estar docente: a sala de aula e a saúde dos professores. Bauru: Edusc, 1999.

FLECK, M. P. A. et al. Desenvolvimento da versão em português do instrumento de avaliação de qualidade de vida da OMS (WHOQOL-100). Revista Brasileira de Psiquiatria, São Paulo, v. 21, n. 1, p. 19-28, jan./mar. 1999.

FRANCO, M. E. D. P.; MOROSINI, M. C. Redes acadêmicas e produção do conhecimento em educação superior. Brasília: INEP, 2001.

FREIRE, P. Pedagogia da autonomia: saberes necessários a prática educativa. São Paulo: Paz e Terra, 1996.

GIL, A. C. Como elaborar projetos de pesquisa. 4. ed. São Paulo: Atlas, 2006.

MORENO-JIMENES, B. et al. A avaliação do Burnout em professores. Comparação de instrumentos: CBP-R e MBI-ED. Psicologia em Estudo, Maringá, v. 7, n. 1, p. 11-19, jan./jun. 2002.

LIMONGI-FRANÇA, A. C.; RODRIGUES, A. L. Stress e trabalho: uma abordagem psicossomática. 3. ed. São Paulo: Atlas, 2002. 
LIMONGI-FRANÇA, A. C. Qualidade de vida no trabalho - QVT: conceitos e práticas nas empresas da sociedade pós-industrial. São Paulo: Atlas, 2004.

LIMONGI-FRANÇA, A. C.; RODRIGUES, A. L. Stress e trabalho: uma abordagem psicossomática. 4. ed. São Paulo: Editora Atlas, 2005.

LIMONGI-FRANÇA, A. C. Psicologia do trabalho: psicossomática, valores e práticas organizacionais. São Paulo: Editora Saraiva, 2008.

LIPP, M. E. N.; ROCHA, J. C. Stress, qualidade de vida e hipertensão arterial. Campinas: Papirus, 1996.

LIPP, M. N. Stress, Hipertensão Arterial e Qualidade de Vida: Um guia de tratamento para o hipertenso. Campinas: Papirus, 1994.

MICHAELIS: moderno dicionário da língua portuguesa. São Paulo: Melhoramentos, 1998. $2267 p$

MOLINA, O. Estresse no cotidiano. São Paulo: Pancast, 1996.

NAHAS, M. V. Atividade física, saúde e qualidade de vida: conceitos e sugestões para um estilo de vida ativo. Londrina: Midiograf, 2006.

PNUD - Programa das Nações Unidas para o Desenvolvimento. Disponível em: <http://www.pnud.org.br//DH/DH.aspx>. Acesso em: 10 maio 2015.

RICHARDSON, R. J. Pesquisa social: métodos e técnicas. 3. ed. São Paulo: Atlas, 1999.

ROSSI, A. M.; QUICK, J. C.; PERREWÉ, P. L. Stress e qualidade de vida no trabalho: o positivo e o negativo. São Paulo: Editora Atlas, 2009.

SILVA, F. P. P. Burnot: um desafio à saúde do trabalhador. Revista de psicologia social e institucional, Londrina, v. 2, n. 1, jun. 2000. Disponível em: <http://www.uel.br/ccb/psicologia/revista/textov2n15.htm>. Acesso em: 09 abr. 2015.

WHOQOL GROUP. The World Health Organization Quality of Life Assessment: position paper from the World Health Organization. In: Social Science \& Medicine. v. 41, p. 14031410, 1995. 